\title{
Visual Analysis of Data Sales Using the Knime Platform Template - A Study at PT. Soho Global Health Alliance Division Cirebon
}

\author{
Eman Sulaiman $^{1}$, Suliyanto $^{2}$, Najmudin $^{3}$ \\ \{emans.aero@gmail.com ${ }^{1}$, suli_yanto@yahoo.com ${ }^{2}$, najmudin_najmudin@yahoo.com $\left.{ }^{3}\right\}$ \\ Doctoral Student Faculty of Economics and Business, Universitas Jenderal Soedirman, Indonesia, \& STIE \\ Cirebon, Indonesia ${ }^{1}$, Faculty of Economics and Business, Universitas Jenderal Soedirman, Indonesia ${ }^{2}$, Faculty of \\ Economics and Business, Universitas Jenderal Soedirman, Indonesia ${ }^{3}$
}

\begin{abstract}
Industry 4.0 Era data is very important and is the starting point for managers to make decisions on the next step. Sales data generally have been presented and processed using Ms. Excel. This has limitations in visualizing, the purpose of this study is to bridge the limitations of the author by conducting a visual study of sales data analysis using the open-source KINIME Platform template. The results show that using KNIME Data visualization can be done easily and quickly (drag and drop node) using the template provided. The empirical advantage of this study is that it makes it easier for target managers to manage data, and big data is used as a basis for companies to plan everything. Theoretically adding knowledge about big data to marketing theory. Future research in The database can be used for terms of machine learning and artificial intelligence for marketing.
\end{abstract}

Keywords: Industry 4.0”, "Marketing”, "Sales Data”, "KNIME”, “Visual Analysis”.

\section{$1 \quad$ Introduction}

PT. Soho Global Health has served the marketing of its pharmaceutical products to hundreds of cities in Indonesia. Each city contains several business circles, each of which has different marketing characteristics. It is a common concern of modern enterprises to accurately excavate the dynamic information of the business circles from the market data for specific products and business circles, grasp the trends of consumer demand promptly, integrate business scenes, products, and big data organically and provide consumers with new user experiences and precise services according to specific products and business circles [1]. Sales information data examination assumes an inexorably significant job in significant business choices of present-day undertakings intelligent decisions [2]. 
For instance, in the business of the pharmaceutical industry, it is especially essential to complete the examination of deals information because of the restriction of the creation cycle and crisp keeping period, etc and it can lessen the misfortune and increment the benefits. With the appearance of the period of enormous data [3]. Sales data presents information to be evaluated and can be used to make decisions for marketers that Client experience has risen as a wellspring of practical serious separation. Late improvements in huge information investigation have opened the likelihood to open client bits of knowledge for clients experience the board [4]. [5] characterized Data Perception as utilizing a PC bolstered, intelligent [2], visual portrayal of dynamic information to upgrade intellectual abilities.

The majority of the endeavor data frameworks and business the board frameworks are multi-dimensional information. [6] summed up data representation techniques. In down to earth applications, the piece of information will in general become progressively convoluted. A solitary perception and visual investigation strategy can't fulfill the interest of its examination.

Visual examination accepts people as the fundamental group of investigation and request, accentuating examination techniques dependent on human PC communication and accords with human's psychological law, and hopes to incorporate the subjective aptitudes that people have and machines are bad at [6], [7]. As of late, a few researchers at home and abroad have been committed to the representation of large information in various fields and have acquired comparing research results. [8]-[10] in urban transportation, digital security, online networking, and different fields all have some exploration progress. [11] utilization of representation innovation to break down and comprehend the exercises of versatile clients, [12] set forward utilizing bunching calculation to picture spatial-worldly web of things information in the procedure of horticultural item flow, [13] investigation and perception of cigarette-deals information dependent on ETL.

As of now, the visual examination explicitly focused at the retail advertise at pharmaceutical item are still generally uncommon. The coordination of perception innovation and human PC communication can understand the connection between the client and the information, with the goal that the client can all the more likely use and control the information [14]. Instructions to manage high-dimensional huge information are one of the significant difficulties right now confronting the field of information visual examination [15]. The importance of visualizing the data corroborated by research [16] the wrong visual data will cause less prediction. 
Until now the author's knowledge of how to deliver sales data visualization is still limited in MS. Excel [17] and no one has been present using certain algorithm software, especially on KNIME software [18]. This study focuses on the method of data visualization using a platform template from KNIME. Because the previous research described above has not examined the visual analysis of sales data of pharmaceutical companies using the KNIME platform and usefulness and effectiveness of this system [19].

Simple statistics to big data analytics, the purpose of this study is because of the existence of a research gap and the need for research development (or to solve existing research problems), the purpose of this study is to bridge the limitations of the author by conducting a visual study of sales data analysis using the open-source KINIME Platform template.

\section{$2 \quad$ Literature Review}

\subsection{Visualization methods}

Perception techniques are used to make tables and outlines to get information. Enormous information perception is more troublesome than customary little information representation in light of the unpredictability of the four verses [6], [20], [21]. For large information perception, a few analysts have applied a bunch mode programming to acquire the most elevated information goals in an equal way [22]. Information introduction is significant in managing large information. In [23] the creators proficiently pictured enormous scope information. Information investigation procures information about market patterns. Item proposals are given after breaking down occasional varieties. Investigation of information recognizes deceitful cases.

For advancement purposes, an examination can help in deliberately setting notice [24]. Also, large information prescient examination empowers individuals to settle on an important choice as to the comprehension of clients and items. What's more, information investigation recognizes potential dangers and open doors for an organization. The wellbeing division can anticipate an improvement by uncovering concealed examples from a lot of human services information. The constant examination of social insurance information can bring about improving clinical administrations to the patients.

Additionally, a patient's reaction to a medication treatment may likewise enable pharmaceutical organizations to concur on tranquilize advancement. Truth be told, a 
huge information examination can enable pharmaceutical organizations to customize a medication for every patient to guarantee better and quicker recuperation. Then again, the web has created a blast of substance, which comprises of flooding content, sound, pictures, and recordings. Numerous potential procedures can be actualized to improve, characterize, and sort out substance with the advances for a lot of information. These procedures permit individuals to secure applicable and logical data through a brought together access framework. Basic programming or equipment can't deal with or oversee numerous assignments; thus, huge information the board frameworks are required [25].

\subsection{Data Understanding}

Data is a record of an occasion or an exchange, which happens when you buy an item or answer to showcasing advancement. In its easiest structure, sending an instant message or tapping on a site itself is a type of exchange [26]. Big data is a collection of structured and unstructured data that correspond to various activities. Structured data entails data that is categorized and stored in a file according to a particular format description, such as data held in relational databases and spreadsheets.

PCs and tablets that are associated with Internet-related stages, (for example, online networking, different site mediums, and publicizing through video stages) produce numerous sorts of data. Both industry and government currently give checking advancements that read vitality utilization, track social insurance related visits and movement, and record your movement action to make data information. Customary stages, spreadsheets, electronic accommodation of record types, and choice help stages, for example, information warehousing and information data mining despite everything assume a job too [27].

\subsection{Data Acquisition}

Gaining access to data you want for modeling is not as easy as it might seem. Many companies have portions of the data you need to be stored in different data "silos." The separate data stores may exist in different departments, in spreadsheets, miscellaneous databases, printed documents, and handwritten notes. The initial challenge is to identify where the data are and how you can get it. If your data are all in one place (such as in a data warehouse), you still must determine the best way to access it. If the required data are in one or more database structures, there are three 
common modes of access to business data One of which is Query-based data extracts from the database to flat files [28].

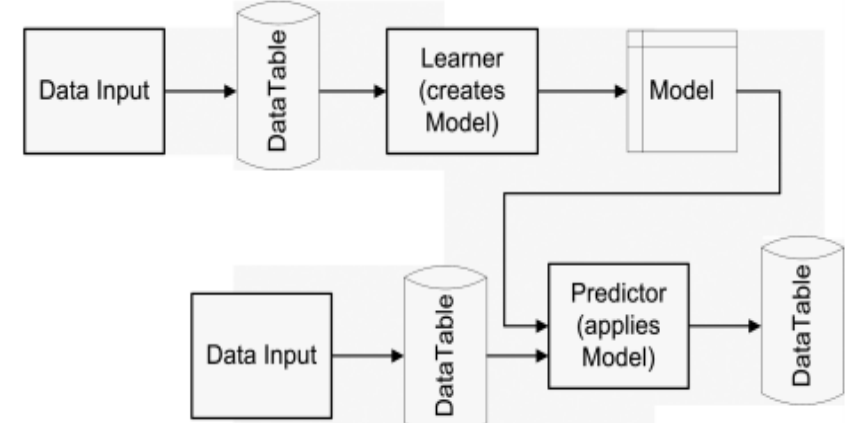

Figure 1. A schematıc tor the progression of intormation and models in a Knıme worktıw (Michael R. Berthold et al., 2019).

Figure 1. schematically shows this procedure. The kind of handling ranges from basic information tasks, for example, separating or converging to progressively complex measurable capacities, for example, calculations of mean, standard deviation or straight relapse coefficients to calculation serious information demonstrating administrators (bunching, choice trees, neural systems, to give some examples). Likewise, a large portion of the demonstrating hubs permits to intuitively investigate their outcomes by going with sees [29].

\subsection{Data Profiling and cleansing}

In KNIME input data from an excel file through the "file reader" node by dragging and dropping into the workbench, file save using CSV extension but before inputting the data it must be rechecked to avoid: The focal propensity of information in the variable, an expected anomalies. The number and conveyance of spaces over all the cases, Any dubious information, as miscodes, preparing information, or outright trash Your discoveries ought to be introduced as a report and recorded as an achievement in the venture plan [28]. Following the cleaning, the information should be exposed to psychometric examinations if scales are utilized in the investigation. The unwavering quality, legitimacy, and absence of predisposition as talked about in past areas of this article should be analyzed. Thing investigations can be directed on scales if fundamental [30]. 
Information purifying incorporates tasks that right terrible information swift some awful information through of the informational index, and channel out information that is unreasonably pointed by point for use model in this research. The human contribution of information is dependent upon mistakes [28], [31]. Additionally, a few codes are not in current use. On either occasion, and we as researchers discuss the substance of every factor in all records to ensure that the entirety of the substance is substantial sections for every factor. Numerous information mining devices give data profiling abilities. For instance, KNIME we can drag and drop Clementine gives the conveyance hub, which yields a rundown of potential information esteems for absolute factors, along with the rate events [28].

\subsection{Knime Analytics Platform}

\subsubsection{About KNIME}

At KNIME®, was fabricate programming for quick, simple, and natural access to cutting edge information science, helping associations drive development. Our KNIME Analytics Platform is the main open answer for information-driven advancement, intended for finding the potential covered up in information, digging for new experiences, or anticipating new prospects. Associations can take their cooperation, profitability, and execution to the following level with a hearty scope of business expansions to our open-source stage. For longer than 10 years, a flourishing network of information researchers in more than 60 nations has been working with our foundation on each sort of information: from numbers to pictures, particles to people, signs to complex systems, and straight forward measurements to enormous information investigation. KNIME's base camp is situated in Zurich, with extra workplaces in Konstanz, Berlin, and Austin, and Austin, and open for innovation ${ }^{\circledR}[18]$.

\subsubsection{KNIME Workbench}

The first thought which supports the workbench is the framework graph [32], In the workbench, there is a covering around the real model. This covering presents a steady interface to the underlying model that different pieces of the Modeling Workbench can utilize. This interface empowers running the reproduction model as though it were a capacity.

KNIME workbench can be seen in Figure 2, showing there are seven sections of the KNIME platform interface or the so-called workbench, this section can be changed according to the needs of researchers. KNIME Explorer is an overview of 
the variable workflows and workflow groups in the active KNIME workspaces. Workflow Coach is a list of node recommendations based on the workflow built by the wide community of KNIME users. Node Repository is an All nodes available in core KNIME Analytics Platform and in the extensions you have install are listed here. The nodes are organized by categories but you can also use the search box to find nodes. The description is a Description of the currently active workflow ar a selected node. The outline is an overview of the currently active workflow. The console is a Show execution message. Indicating What is going on under the hood [33].

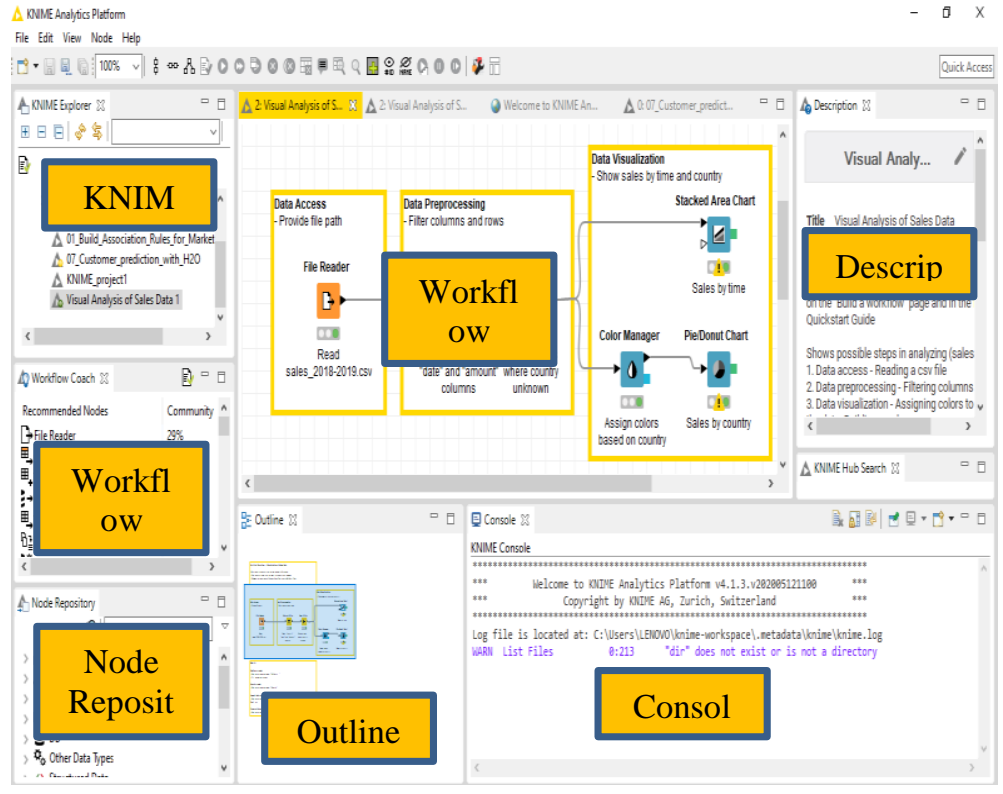

Figure 2. The KNIME Analytics Platform user interface - KNIME workbench

\subsubsection{KNIME workflow}

A workflow is an information examination arrangement, which is a customary programming language that would be actualized by a progression of directions and calls to capacities. KNIME actualizes it graphically. This graphical portrayal is increasingly instinctive to utilize, lets you keep a diagram of the investigation procedure, and makes for the documentation too. KNIME actualizes its work processes graphically. Each progression of the information examination is actualized 
and executed through a little box, called a node. An arrangement of nodes makes a workflow [34].

According to Work processes in Knime are charts associating hubs, or all the more officially, a direct non-cyclic diagram (DAG). The Workflow Manager permits to embed new hubs and to include coordinated edges (associations) between two hubs. It likewise monitors the status of hubs (designed, executed,...) and returns, on request, a pool of executable nodes. This way the encompassing structure can unreservedly distribute the outstanding burden among two or three equal strings or later on - even a conveyed group of servers. Because of the fundamental chart structure, the work process director can decide all hubs required to be executed along the ways prompting the hub the client needs to execute [29].

A workflow is an investigation stream, for example, the succession of investigation steps important to arrive at a given outcome. It is the pipeline of the investigation procedure, something like Step 1. Read data, Step 2. Clean data, Step 3. Filter data, Step 4. Train a model [29].

\subsubsection{Node in KNIME}

A node is the single handling unit of a work process [34]. A node in Knime is the broadest handling unit and normally looks like one visual hub in the work process [29]. The class Node wraps all usefulness and utilizes client characterized usage of a Node Model, perhaps a Node Dialog, and at least one Node View occasions if suitable A node takes an informational index as information, forms it, and makes it accessible at its yield port. The "handling" activity of a hub ranges from demonstrating - like an Artificial Neural Network Learner hub - to information control - like transposing the info information framework - from graphical apparatuses - like a disperse plot, to perusing/composing tasks. Each hub in KNIME has 4 states [29], [34]: (1) Inactive and not yet configured $\rightarrow$ red light. (2) Configured but not yet executed $\rightarrow$ yellow light. (3) Executed successfully $\rightarrow$ green light. (4) Executed with errors $\rightarrow$ red with cross light.

Nodes containing other nodes are called meta nodes [33]. Figure 3 explains

the node's port in KNIME and node status. Every Node can have a subjective number of perspectives related to it. Through getting occasions from a HiLite Handler (and sending occasions to it) it is conceivable to check (the purported HiLiting) choice focuses on such a view to empower visual brushing. Perspectives can extend from straightforward table perspectives to progressively complex perspectives on the hidden information or the created model [33]. 


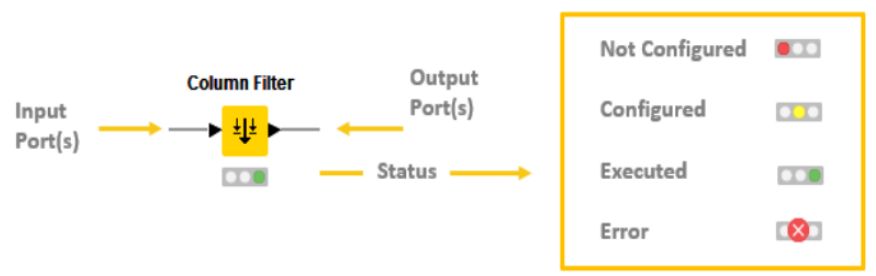

Figure 3. Node port and status in KNIME

\section{$3 \quad$ Methode}

The applied of the research to address a specific concern using data sales from Active practitioners (sales representatives) [35], Research Types this study Descriptive research. According to Newman Descriptive research is Examination in which the main role is to "paint an image" utilizing words or numbers and to introduce a profile, an order of types, or a diagram of steps to respond to addresses, for example, who, when, where, and how [35].

The research design using the well-known basic management theory is input process output [36] which is applied to the platform which can be seen in Figure 4. Research layout. The picture is divided into three parts including input data, process data, and output data using science software and analytic tools KINIME.

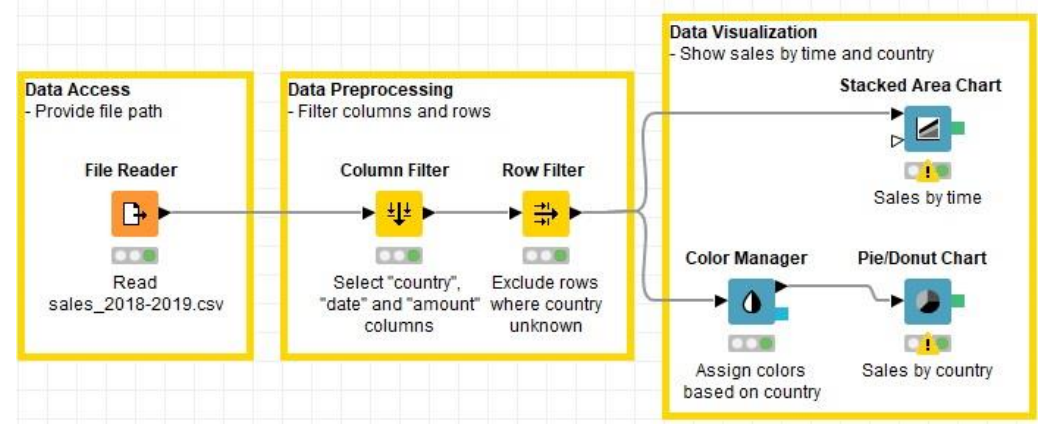

Figure 4. Research template design 


\subsection{Procedure}

First, data access is input data that will be examined, using Ms. Excel and saved first using the CSV format in the following way; drag and drop the file reader from the workflow coach, then click at right in the "file reader" $\rightarrow$ click configure $\rightarrow$ browse $\rightarrow$ OK. At that time the indicator light was still yellow. To recuperate the algorithm data we must RUN by right-clicking: "file reader" $\rightarrow$ Execute, if the input data is correct then the indicator light will turn green.

Second, at this stage is the data preprocessing, the nodes needed for this process are the column filter node and the row filter node. For setting the column node filter, you can do this by right-clicking on the node "column filter" $\rightarrow$ click configure A dialog box will appear in exclude select row ID, Product, quantity, and Host ID, in the included box select City, date amount then click OK. For the RUN execution, we need to connect the pipeline from the file reader node to the column filter node by dragging the line from the black triangle mark from the file reader directed to the column filter node, the next step right-click execute and the light indicator appears to turn green.

Furthermore, data preprocessing second node row. Right-click the filter row and a dialog box will appear, in the filter criteria check the column that will be tested with the "city" option and click ok. For the RUN execution, we need to connect the pipeline from the file reader node to the row filter node by dragging the line from the black triangle mark from the column filter directed to the row filter node, the next step right-clicks execute and the light indicator appears to turn green.

\subsection{Data}

An information examination process comprises of a pipeline of a node [33], associated by edges that transport either information or models. Every hub forms the showing up information or potentially model(s) and produces results on its yields. In this paper, the data used are the results of real data from the sales data for the period of June 2018 to June 2019. The data collected in the form of the date of the transaction, the name of the outlet, the name of the product, and the city of the outlet. The data is then processed according to the needs of the input data at KNIME.

\subsection{Analysis}

The results of executing a computer program running the data inputted, and calculated by the algorithm available on the KNIME platform, the results of sales 
data visualization based on the time using a stacked chart with the results in Figure 5. The graph is estimated to be related to sales every month, where the marketing staff (medical representatives) who are required to achieve the sales target requested by the company.

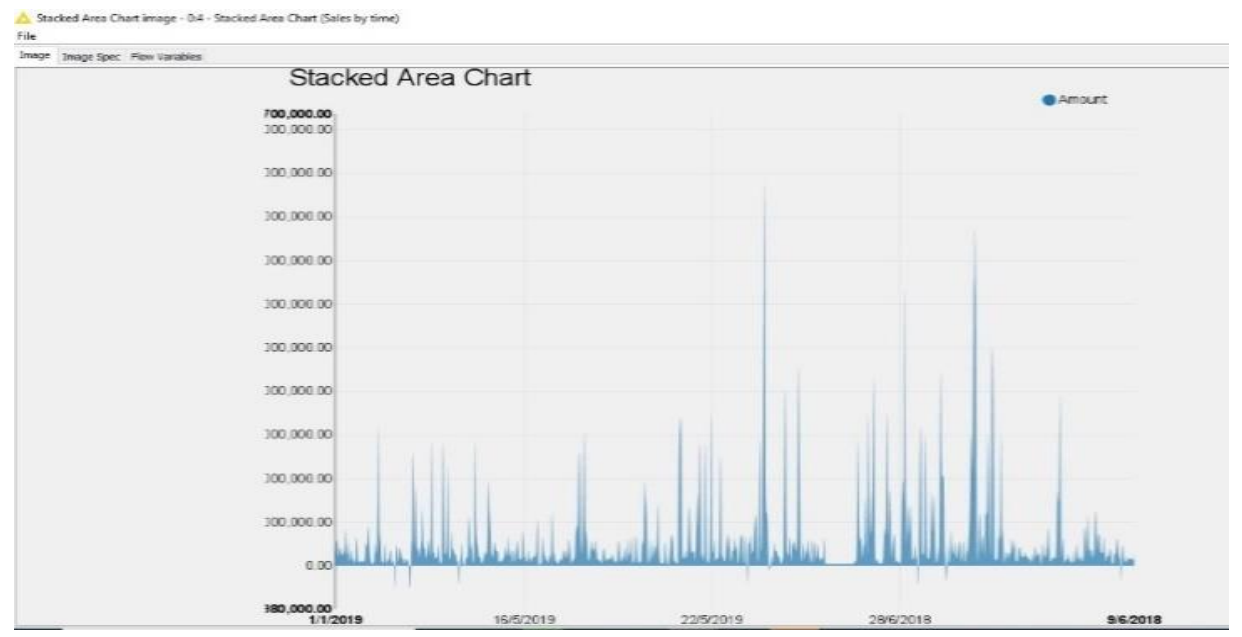

Figure 5. Output - Stacked Chart

Furthermore, for visual data results from sales data based on cities Furthermore, for visual data results from sales data based on cities in figure 5 , in this study conducted in 4 cities, namely the city and district of Cirebon. Majalengka Regency, Kuningan Regency, and Indramayu Regency. It can be seen that the biggest sale occurs in the city/regency of Cirebon. 


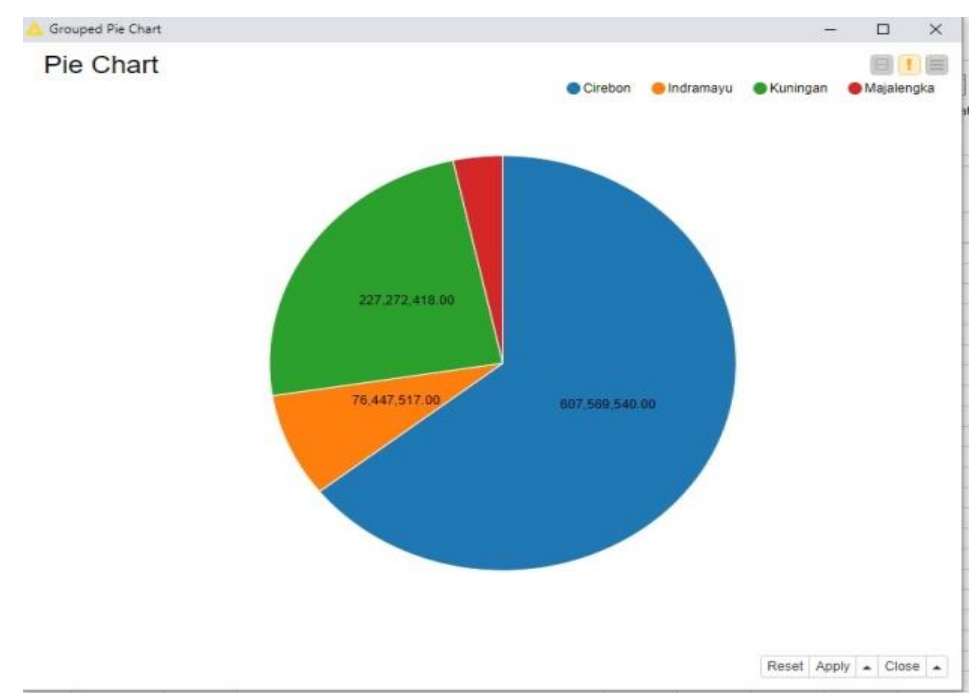

Figure 6. Distribution Sales by City

\section{$4 \quad$ Result and Discussion}

The results of the output stacked chart show the highest rising trend in May 2019 touching 20,700,000. The second highest is from the sales data for April 2019 with a total sales value of $19,205,120$, the cause of this unnatural result is sudden market demand without being based on power forces bargaining marketing so that sales occur only 1 or 2 times only and cannot be used as monthly traffic. With fluctuating results [37] high, the performance of marketing does not reach the targets that have been made because of uneven sales distribution. According to research [38] which states that a proactive market and market vision has a positive influence on sales per company and the growth rate of a company. This is a challenge for leaders to take the next decision [39].

For a pie chart consisting of 4 cities with the following results; The blue color of the city of Cirebon with total sales data of 607,609,540, these results indicate the achievement of sales in the city of Cirebon is the largest contribution with a figure of 64,38 percent. green color Kuningan city total sales data amounted to $227,272,418$ or 24 percent of total sales, Brown Color Indramayu city with total sales data 76,447,517 with a contribution of 8,1 percent, red color Majalengka city with a total sales data of $32,364,157$ with contributions the smallest is 3,4 percent. 
With different levels of data distribution ranging from minus 19,800,000 data and the highest data of 20,700,000, if done using linear equations it can be difficult because of the difference in the range of values, therefore it requires a machine learning platform template that automates it automatically [40].

\section{Conclusion}

The results of the findings contribute to the literature in terms of how to present sales data for a company with a different perspective. In this paper sales, data are processed using the KNIME platform, by presenting output in the form of a stacked chart and pue chat, in the future other models that are needed for specific purposes can be developed. Future research can explain for this template and develop predictive customer service building models, predict sales targets, predict demand, and this research can also be basic for machine learning for marketing.

\section{Implication/Limitation and Suggestions}

The implication of this research is for decision-making leaders in sales and can see a dashboard chart with a different perspective and can be useful in making future decisions. This research is useful for theoretical, especially marketing concentrations, currently, the industry 4.0 era where computerization, digitalization, automation is a must, the country also with marketing theory that continues to evolve combining elements of sales marketing database with a platform software to produce a new perspective in analyze data.

Every research must have limitations, this paper is no exception. First, the data used are real sales data of pharmaceutical companies. so the limitations of the data obtained are local 4 cities, namely the city of Cirebon, the City of Majalengka, the city of Kuningan, and the City of Indramayu, in the future it is necessary to research with large-scale data. Secondly, regarding the KNIME Platform that is used by the assessment, currently, only templates are available, in the future it can create innovations with a variety of workflow arrangements following the needs. 


\section{References}

[1] K. Zhao, R. Sun, C. Deng, L. Li, Q. Wu, and S. Li, "Visual Analysis System for Market Sales Data of Agricultural Products," IFAC-PapersOnLine, vol. 51, no. 17, pp. 741-746, 2018, doi: 10.1016/j.ifacol.2018.08.107.

[1] K. Zhao, R. Sun, C. Deng, L. Li, Q. Wu, and S. Li, "Visual Analysis System for Market Sales Data of Agricultural Products," IFAC-PapersOnLine, vol. 51, no. 17, pp. 741-746, 2018, doi: 10.1016/j.ifacol.2018.08.107.

[2] H. Li, Y. J. Wu, and Y. Chen, "Time is money: Dynamic-model-based time series data-mining for correlation analysis of commodity sales," J. Comput. Appl. Math., vol. 370, p. 112659, 2020, doi: 10.1016/j.cam.2019.112659.

[3] L. Alexandros and H. V. Jagadish, "Challenges and opportunities with big data.," in Proceedings of the VLDB Endowment, 2012, pp. 5(12), 2032-2033.

[4] M. Holmlund et al., "Customer experience management in the age of big data analytics: A strategic framework," J. Bus. Res., no. January, pp. 1-10, 2020, doi: 10.1016/j.jbusres.2020.01.022.

[5] S. K. Card, J. D. Mackinlay, and B. Shneiderman, Readings in information visualization: using vision to think. Morgan Kaufmann, 1999.

[6] D. Keim, H. M. Qu, and K. L. Ma, "Big-data visualization," IEEE Comput. Graph. Appl., vol. 33, no. (4), pp. 20-21, 2013.

[7] L. Ren, Y. Du, S. Ma, X. L. Zhang, and G. Z. Dai, "Visual analytics towards big data," J. Softw., vol. 25, no. (9), pp. 1909-1936, 2014.

[8] F. Wang et al., "A visual reasoning approach for data-driven transport assessment on urban roads.," in In IEEE Conference on Visual Analytics Science and Technology (VAST), 2014, pp. 103-112.

[9] N. Ferreira, J. Poco, H. T. Vo, J. Freire, and C. T. Silva, "Visual exploration of big spatio-temporal urban data: A study of new york city taxi trips," IEEE Trans. Vis. Comput. Graph., vol. 19, no. (12), pp. 2149-2158, 2013.

[10] D. Murthy, A. Gross, and M. McGarry, "Visual Social Media and Big Data. Interpreting Instagram Images Posted on Twitter.," Digit. Cult. Soc., vol. 2, no. (2), pp. 113-134, 2016.

[11] H. Y. Jiang, Y. D. Wu, W. X. Zhao, and K. Tang, "Mobile data visual analysis for human activity understanding.," J. Zhejiang Univ. (Science Ed. ), vol. 45, no. (1), pp. 37-43, 2018.

[12] C. F. Lin, P. H. Yu, and Z. Y. Li, "Using clustering algorithm to visualize spatial temporal internet of things data in process of agricultural product circulation.," Trans. Chinese Soc. Agric. Eng., vol. 31, no. (3), p. $228-235,2015$.

[13] D. Guo and H. Fan, "Analysis and Visualization of Cigarette Sales Data Based on ETL-KETTLE.," Comput. Syst. Appl., vol. 26, no. (1), pp. 74-80, 2017.

[14] Q. Wu, C. Deng, R. Sun, K. Zhao, and S. Li, "Multi-dimensional Information Visualization Analysis of Business Circles and Products Based on Density Clustering," IFAC-PapersOnLine, vol. 51, no. 17, pp. 811-816, 2018, doi: 10.1016/j.ifacol.2018.08.095.

[15] H. . Chen et al., "Uncertainty-aware multidimensional ensemble data visualization and exploration.," IEEE Trans. Vis. Comput. Graph., vol. 21, no. (9), pp. 1072-1086, 2015.

[16] M. R. Blake, S. Dubey, J. Swait, E. Lancsar, and P. Ghijben, "An integrated modelling approach examining the influence of goals, habit and learning on choice using visual attention data," J. Bus. Res., vol. 117, no. April, pp. 44-57, 2020, doi: 10.1016/j.jbusres.2020.04.040.

[17] K. Melcher, From Excel to KNIME. Zurich, Switzerland: KNIME Press, 2018.

[18] M. R. Berthold et al., " $\{\mathrm{KNIME}\}$ : The $\{\mathrm{K}\}$ onstanz $\{\mathrm{I}\}$ nformation $\{\mathrm{M}\}$ iner," 2007.

[19] Y. Du, H. Yin, C. Wang, and C. Li, "Visual analysis of customer switching behavior pattern mining for takeout service," J. Comput. Lang., vol. 57, p. 100946, 2020, doi: 10.1016/j.cola.2020.100946.

[20] B. Geng, T. Li, Y., M. D., Wang, Z. J. Zha, and C. Xu, "Parallel lasso for large-scale video concept 
detection.," IEEE Trans. Multimed., vol. 14, no. (1), pp. 55-65, 2012.

[21] J. Heer, J. Mackinlay, C. Stolte, and M. Agrawala, "Graphical histories for visualization: Supporting analysis, communication, and evaluation.," IEEE Trans. Vis. Comput. Graph., vol. 14, no. (6), pp. 1189-1196, 2008.

[22] K.-L. Ma and S. Parker, "Massively parallel software rendering for visualizing large-scale data sets.," IEEE Comput. Graph. Appl., vol. 21, no. (4), pp. 72-83, 2012.

[23] D. Thompson et al., "Analysis of large-scale scalar data using hixels. In Large Data Analysis and Visualization (LDAV)," IEEE Symp., pp. 23-30, 2011.

[24] S. Aissi, P. Malu, and K. Srinivasan, "E-business process modeling: The next big step.," Computer (Long. Beach. Calif)., vol. 35, no. (5), pp. 55-62, 2002.

[25] I. Yaqoob et al., "Big data: From beginning to future," Int. J. Inf. Manage., vol. 36, no. 6, pp. 12311247, 2016, doi: 10.1016/j.ijinfomgt.2016.07.009.

[26] S. Kudyba, Big data, mining, and analytics: components of strategic decision making. Boca Raton: CRC Press, Taylor and Francis., 2014.

[27] P. H. Park, Big data war: how to survive global big data competition, (First edi. New York: Business Expert Press, 2016.

[28] Nisbet, Handbook of Statistical Analysis and Data Mining Applications. Elsevier Inc, 2018.

[29] N. C. Michael R. Berthold et al., "Knime: The Konstanz Information Miner," Konstanz, Germany, 2019.

[30] C. Foxcroft and G. Roodt, An introduction to psychological assessment in the South African context, 4th ed. Oxford, UK: Oxford University Press, 2013.

[31] H. Che, S. Zeng, and J. Guo, "Reliability assessment of man-machine systems subject to mutually dependent machine degradation and human errors," Reliab. Eng. Syst. Saf., vol. 190, no. November 2018, 2019, doi: 10.1016/j.ress.2019.106504.

[32] J. H. Kwakkel, "Environmental Modelling \& Software The Exploratory Modeling Workbench: An open source toolkit for exploratory modeling, scenario discovery, and ( multi-objective ) robust decision making," Environ. Model. Softw., vol. 96, pp. 239-250, 2017, doi: 10.1016/j.envsoft.2017.06.054.

[33] K. AG, KNIME Workbench Guide, 4.1. Zurich, Switzerland, 2019.

[34] R. Silipo, A Guide to KNIME Analytics Platform for Beginner,. Zurich, Switzerland: KNIME PRESS, 2019.

[35] W. L. Neuman, Social Research Methods: Qualitative and Quantitative Approaches, Seventh Ed. England: Pearson Education Limited, 2014.

[36] H. Fayol, "General principles of management," Class. Organ. theory, vol. 2, no. 15, pp. 57-69, 1916.

[37] P. J. Glandon, "Sales and the (Mis)measurement of price level fluctuations," J. Macroecon., vol. 58, pp. 60-77, 2018, doi: 10.1016/j.jmacro.2018.08.012.

[38] D. Gotteland, J. Shock, and S. Sarin, "Strategic orientations, marketing proactivity and firm market performance," Ind. Mark. Manag., no. February, pp. 1-11, 2020, doi: 10.1016/j.indmarman.2020.03.012.

[39] Y. Wang, "When artificial intelligence meets educational leaders' data-informed decision-making: A cautionary tale," Stud. Educ. Eval., no. October 2019, p. 100872, 2020, doi: 10.1016/j.stueduc.2020.100872.

[40] A. M. Fernández, D. Gutiérrez-Avilés, A. Troncoso, and F. Martínez-Álvarez, "Automated Deployment of a Spark Cluster with Machine Learning Algorithm Integration,” Big Data Res., vol. 1920, p. 100135, 2020, doi: 10.1016/j.bdr.2020.100135. 